\title{
A relação entre as políticas de mudanças climáticas e a produção agrícola no Mato Grosso
}

\author{
The relationship between the policies of climate change and the \\ agricultural production in Mato Grosso
}

\section{Suzana Cristina Lourenço ${ }^{1}$}

1 Doutora pelo Departamento de Geografia Humana da Universidade de São Paulo. E-mail: suzana.c.lourenco@gmail.com

\begin{abstract}
RESUMO: O objetivo deste texto é analisar as políticas de adaptação e mitigação às mudanças climáticas e mudanças ambientais regionais no estado do Mato Grosso. Avaliou-se que estas estão em consonância com a realidade e demandas socioambientais do estado. A partir da relação entre fatores econômicos, sociais e ambientais, refletiu-se sobre a participação das camadas da sociedade civil na temática de mudanças climáticas. Partiu-se da premissa que o Estado (representado pelos sucessivos governos), avançam em agendas pautadas nas prioridades de um grupo hegemônico, fundamentado na agricultura industrial, em detrimento dos outros grupos com menor protagonismo político e econômico.
\end{abstract}

Palavras chave: Redes. Participação. Mudanças climáticas. Política Ambiental. Mato Grosso.

\begin{abstract}
The purpose of this paper is to analyze the mitigation and adaptation policies to climate change and regional environmental changes in the state of Mato Grosso. We evaluate if these policies are consonant with the reality and socio-environmental demands of the citizens. From the relationship between economic, social and environmental factors, we reflect on the participation of civil society layers on the theme of climate change. We start from the premise that the State (represented by its successive governments) have adopted agendas based on the priorities of a hegemonic group, based on industrial agriculture, to the detriment of other groups with less political and economic protagonism.
\end{abstract}

Keywords: Networking. Participation. Climate Change. Environmental policy. Mato Grosso.

Sumário: Introdução - 10 Panorama Econômico e Ambiental Mato-Grossense - 2 A Instituição da Política Estadual de Mudanças Climáticas e os Problemas Socioambientais MatoGrossenses - 3 Limitações do modelo político econômico e suas consequências às políticas estaduais de mudanças climáticas - 4 Das políticas estaduais rurais às políticas às mudanças climáticas mato-grossenses Considerações Finais - Referências. 


\section{INTRODUÇÃO}

Diversos são os fatores relevantes a se considerar no planejamento de políticas destinadas aos efeitos das mudanças climáticas nas diversas regiões e estados brasileiros. Este trabalho reflete sobre o contexto que envolve as decisões políticas de adaptação e mitigação às mudanças climáticas e mudanças ambientais regionais no estado do Mato Grosso. A partir da complexidade de tais relações, investigou-se até onde este processo é, ou, pode ser realmente participativo a todas as classes da sociedade civil organizada.

Considerando a análise gramsciniana da relação entre Estado e sociedade. Localizando-se no materialismo histórico na medida em que se pensa as relações de produção como motriz das relações de classe que, também, se refletem quando no estabelecimento das políticas e ações ao ambiente.

Trouxe-se inicialmente o cenário agroexportador do estado de Mato Grosso e como este está relacionado com os processos de perda ecossistêmica, considerando os desmatamentos. Posteriormente avaliou-se como estas mudanças ambientais se refletem desigualmente entre as classes, aqui representadas de um lado por grandes produtores rurais e, por outro, minorias étnicas e agricultores familiares.

Em seguida, e considerando dentro destas mudanças ambientais globais as potenciais mudanças climáticas subsequentes, abordando as arenas políticas que pensam e planificam quais e por que devem ser tomadas estas ou aquelas ações governamentais. Aí abordou-se, também, para quais classes estas políticas tendem a estar direcionadas. Finalmente foi avaliado as possibilidades de participação social, as hegemonias que se estabelecem nestes processos e as consequências das polarizações de discursos e ações.

\section{PANORAMA ECONÔMICO E AMBIENTAL MATO-GROSSENSE}

O estado do Mato Grosso se destaca como líder na exportação de grãos de espécies oleaginosas. Igualmente desponta como um dos principais estados em termos de degradação dos seus três principais biomas (pantanal, cerrado e Amazônia), levando a impactos ambientais que repercutem regional e nacionalmente. Assim, 23 áreas superiores a 500 hectares tiveram a cobertura vegetal substituída por monoculturas para exportação e pastagens. Segundo dados do PRODES/INPE ${ }^{1}$, o aumento de $40 \%$ no desmatamento estadual se concentra ao longo da rodovia BR-163 (Cuiabá-Santarém).

O gráfico 1 demonstra a trajetória de desmatamento entre os anos de 1988 e 2015. Nota-se que a Amazônia Legal como um todo, onde Mato Grosso e Pará se destacam na supressão da cobertura vegetal, com picos principais de supressão de cobertura vegetal entre 1994, 1996 e 2004 e 2006. Geralmente nestes estados o desmatamento é acompanhado pela substituição das áreas florestadas em pastos e, posteriormente, aproveitadas para expansão de monoculturas para exportação.

1 Os dados completos sobre desflorestamento são de domínio público e podem ser consultados na página http://www.dpi.inpe.br/prodesdigital/prodesmunicipal.php. 
Por isso o acompanhamento das áreas desmatadas pode ser um dos elementos de análise de expansão do agronegócio. No caso mato-grossense, os eventos de novos desmatamentos ocorrem principalmente na região noroeste do estado, onde já há vetores de produção de soja para exportação. Outros estados protagonistas deste aumento são o Amazonas, com $54 \%$ de aumento e Rondônia, com $41 \%$ de crescimento, especialmente na região que compreende as hidrelétricas de Jirau e Santo Antônio (RO).

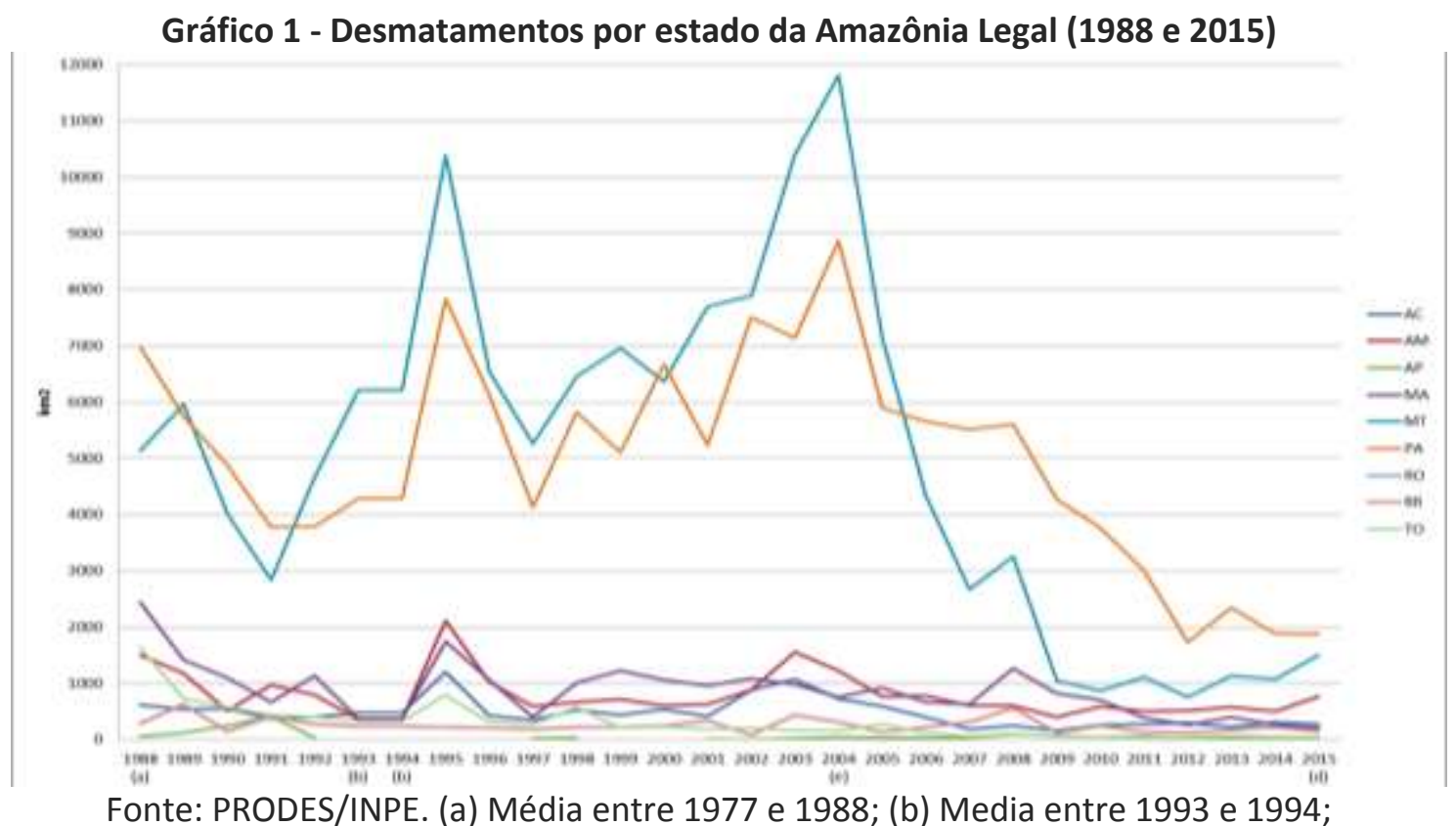

(c) Taxas Anuais Consolidadas; (d) Taxa Estimada; (e) Início PPCDAm.

A pressão nacional e internacional para a redução dos desmatamentos tem levado os sucessivos governos brasileiros a interceder na questão por meio de regulação das terras e planejamento ambiental. Diversas organizações da sociedade civil diretamente afetadas pelos desmatamentos têm apontado os problemas socioambientais que lhes atinge. Estes incluem a perda das características físico-químicas do solo, deriva genética, perda de diversidade, emissão de gases responsáveis pelo efeito estufa e alterações na dinâmica climática que depende das condições de umidade proporcionadas pela floresta em pé.

Diversos programas, políticas e planos vem sendo elaborados pelo Governo Federal, sobretudo a partir de 2000, na tentativa de reverter este quadro. O Cadastramento Ambiental Rural (CAR), por exemplo, é uma ferramenta que se aplica a todos os estados brasileiros e prevê a identificação das áreas onde pode haver desmatamento, definindo também as áreas que devem ser preservadas nas propriedades rurais.

Em vista a uma maior descentralização do Programa, as responsabilidades sobre a autorização e fiscalização dos desmatamentos passaram a ser, em sua maioria, atribuição dos governos estaduais a partir de 2012. Uma vez concluídos, os CAR servem de base para os Planos de Recuperação Ambiental (PRA), gerenciados pelos estados, determinando as ações de restauração florestal nas propriedades. 
Apesar das tentativas governamentais e dos avanços no controle dos desmatamentos por meio de políticas ambientais, os impactos à vegetação natural seguem trazendo desdobramentos negativos. A combinação entre expansão da atividade agroexportadora somada perda de biodiversidade, derivada da fragmentação florestal, por exemplo, são fatores que aumentam a suscetibilidade à emissão de gases de efeito estufa.

O Centro Oeste é responsável por $21 \%$ das emissões de gases nacionais, estando em terceiro lugar no ranking de emissões nacionais (9,3\% das emissões, ou seja, 145,3 Mt CO2 e; 1,6\% da população: 3,2 mi/hab/Km2; 10,6\% da área: 903 mil Km2 e; 4,9\% do PIB: R\$ 71 bi). Os picos de emissões (gráfico 2) condizem com os períodos de maior desmatamento, realizado para ampliar as possibilidades agricultáveis no estado.

Destas emissões, $8 \%$ foram por energias fósseis, $56 \%$ por mudança de uso na terra (destes, $92,4 \%$ por alterações de uso do solo; $3,6 \%$ por calagem e $4 \%$ por queima de resíduos), $34 \%$ de agropecuária, $1 \%$ por resíduos e $1 \%$ pela atividade industrial. Como proposta de redução de emissões, o governo do estado propôs, na $21^{\text {a }}$ Conferência das Partes em Paris, substituir 6 milhões de hectares de pastagens com baixo rendimento em áreas de alta produtividade, compostas por 3 milhões de hectares de plantio de grãos, 2,5 milhões de pecuária e 500 mil de floresta plantada.

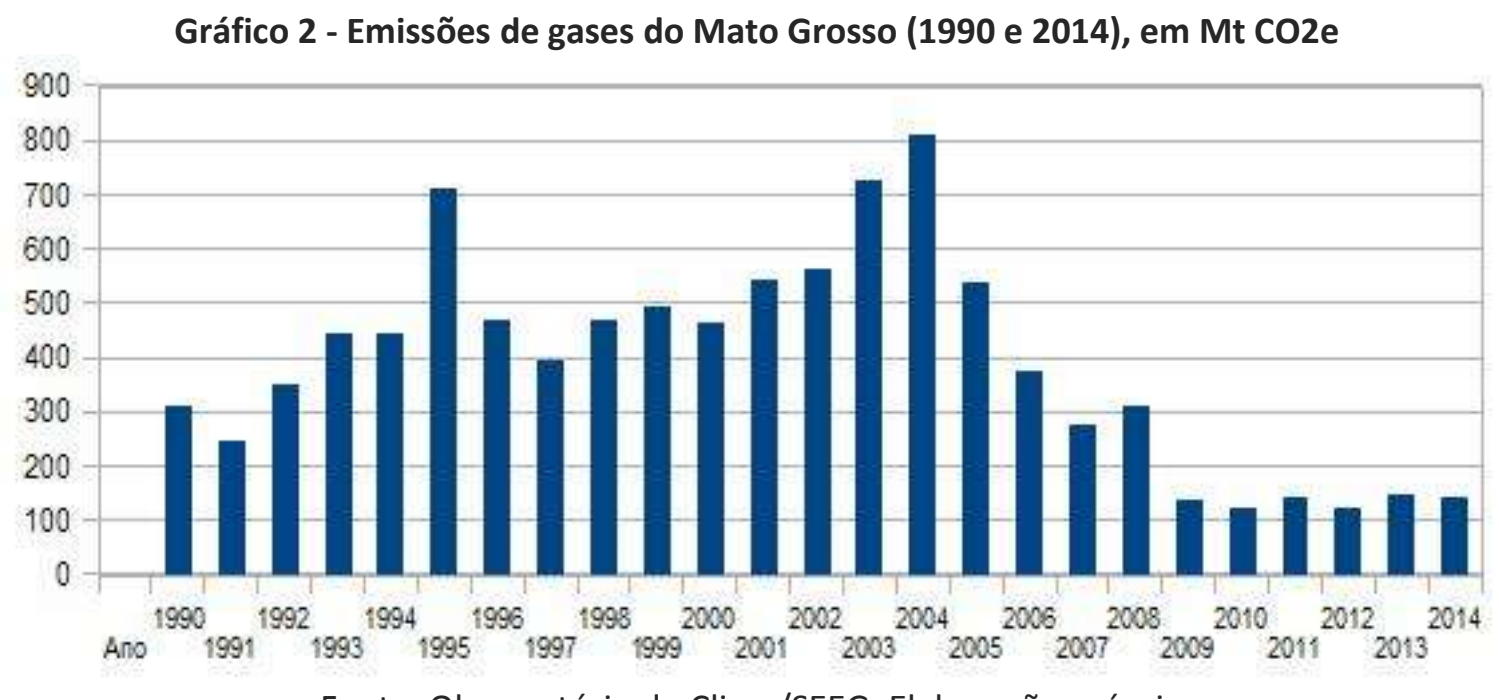

Fonte: Observatório do Clima/SEEG. Elaboração própria.

Na mesma conferência foi proposto, além da contenção do desmatamento, a conservação dos $60 \%$ de vegetação nativa restante no estado e recuperação de 2 milhões de hectares de Áreas de Preservação Permanente (APP). O aumento ao acesso ao crédito e a participação na agricultura familiar no mercado interno de alimentos (de $20 \%$ a $80 \%$ ) e a regularização fundiária em $70 \%$ dos lotes, também, configuraram promessas do governo para mitigação das mudanças ambientais no estado.

Entretanto, estes mesmos objetivos são solapados pela morosidade interna dos instrumentos à política ambiental: a combinação de um zoneamento estadual não condizente com as recomendações técnicas e em desacordo com o estabelecido para a Amazônia Legal, 
os atrasos para a finalização do CAR e o atrelamento destes às novas diretrizes do Código Florestal criaram um cenário de incertezas nas normativas ambientais. Estas indefinições favorecem o avanço agropecuário sobre áreas que deveriam ter graus de proteção, aumentando a vulnerabilidade de grupos sociais que dependem de ambientes com maior harmonia ecossistêmica (ACSELRAD, 2004).

O histórico da ocupação do território nacional ajuda a explicar a origem dos problemas na implementação das políticas ambientais na região. O legado institucional regional consolidado atualmente remonta aos primórdios da colonização, sob forte influência de oligarquias locais que promoveram uma investida econômica e política em um sistema de produção agroexportador, centrado em poucas culturas e anulando pequenas iniciativas agrícolas pela procrastinação do estabelecimento da reforma agrária.

Observa-se que os grupos da sociedade civil inseridos entre os maiores produtores de espécies oleaginosas possuem uma maior permeabilidade nas decisões políticas nesta esfera governamental, isto porque o sistema de tomada de decisões políticas permeia relações de poder que envolve o poder historicamente consolidado de umas classes em relação às outras e uma ciência e tecnologia construídas dentro destas relações de hegemonia (EASTON, 1965; FRIEDRICH, 1963; SHILS, 1958).

Cabe elucidar que a categoria de sociedade política, como intermediação entre sociedade civil e Estado, diz respeito ao âmbito político-administrativo ou institucional, referente às instituições e o controle legal e constitucional, em relação com a sociedade civil por meio dos partidos e sindicatos. Já a sociedade civil é "a esfera das relações entre indivíduos, entre grupos, entre classes sociais, que se desenvolvem à margem das relações de poder que caracterizam as instituições estatais" (BOBBIO, 1998, p.1210). Entretanto, estas definições conceituais individualizadas na teoria, aparecem, na prática, como praticamente um mesmo elemento.

Os grandes produtores agropecuários se destacam na sociedade política e no governo por meio de suas organizações e redes. O protagonismo destes grupos nos processos participativos governamentais estaduais e federais vem de seu papel no Produto Interno Bruto (PIB) estadual, já que a principal exportação no estado do período 2006 - 2014 gira em torno de matéria primas. O Gráfico 3 ilustra os dez principais produtos de exportação do Mato Grosso.

Nota-se o aumento destacado na produção de soja e milho, sobretudo em estado bruto, e diversos derivados da soja de interesse no mercado. Há diminuição da produção de óleo refinado, o que mostra a despreocupação estadual em uma tecnologia para incremento do preço de seus próprios produtos no mercado internacional. 
Gráfico 3. Principais Exportações pelo estado do Mato Grosso entre 2006 e 2015, em US\$ F.O.B (milhões)

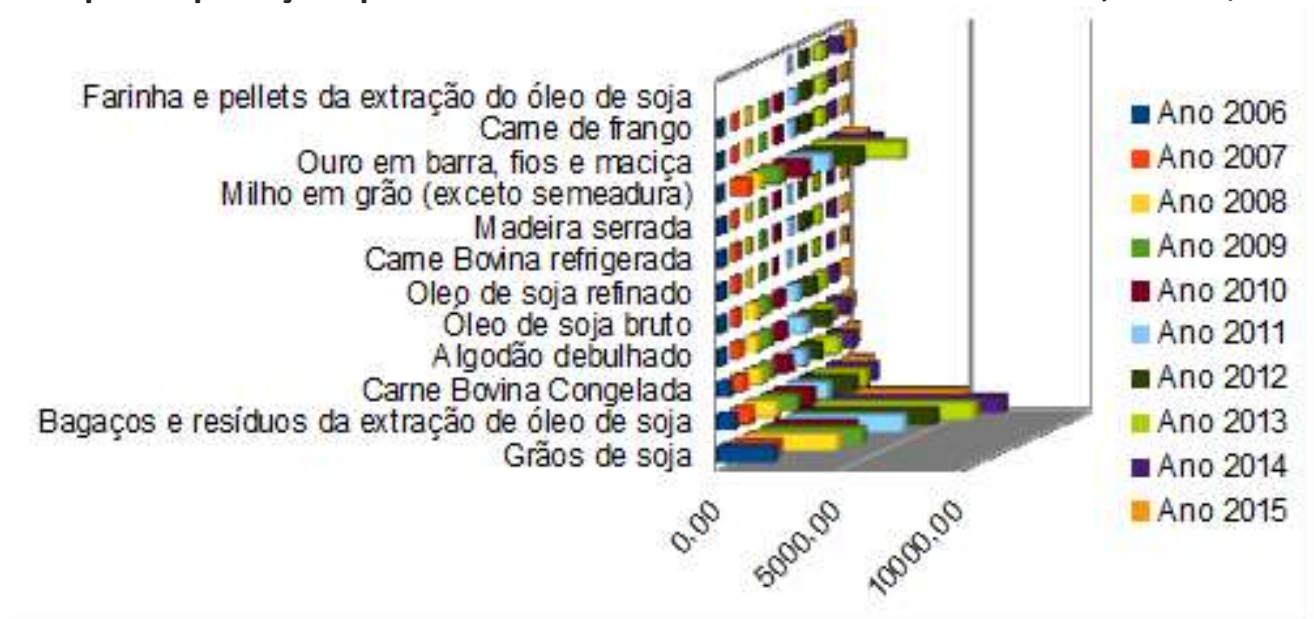

Fonte: Balança Comercial do Ministério do Desenvolvimento Indústria e Comércio Exterior. Formulação própria.

O gráfico 4, por sua vez, mostra um cenário ainda mais preocupante de importação crescente de insumos agrícolas, notadamente fertilizantes, fungicidas e pesticidas. Os fertilizantes representam um problema no balanço energético ecossistêmico. Nas situações de monocultura o balanço energético não se completa, bem como os ciclos de nitrogênio e carbono, diferentemente da cobertura por florestas tropicais, onde os ciclos de nutrientes entre o solo-planta e ar como o nitrogênio e o carbono permanecem balanceados, mantendo o sistema. Já os pesticidas são responsáveis pela extinção de importantes polinizadores e dispersores de sementes, importantes para manter o fluxo gênico das comunidades dentro do ecossistema.

Tal panorama tem levado aos ciclos agrícolas das culturas mais cobiçadas a serem cada vez mais dependentes de insumos agrícolas. Por outro lado, as estratégias de corredores ecológicos e diversificação da produção visando a agrobiodiversidade, como Sistemas Agroflorestais e Agropastoris, se veem cada vez mais comprometidas com a pressão das fronteiras agrícolas e contaminação de solo, fauna e lençóis freáticos, imprescindíveis para a manutenção de pequenos agricultores e comunidades tradicionais locais.

Com isso, as distâncias entre a distribuição dos recursos entre grandes produtores e a sociodiversidade se torna cada vez mais abismal. A reação a esta disparidade é a crescente tentativa de intervenção deste segundo grupo nos processos decisórios, sendo a política de Combate às Mudanças Climáticas uma das vias de acesso às tentativas de busca por maior equidade de acesso aos recursos naturais e sua manutenção. 
Gráfico 4. Principais Importações do Mato Grosso (2006 e 2015) em US\$ F.O.B (milhões)

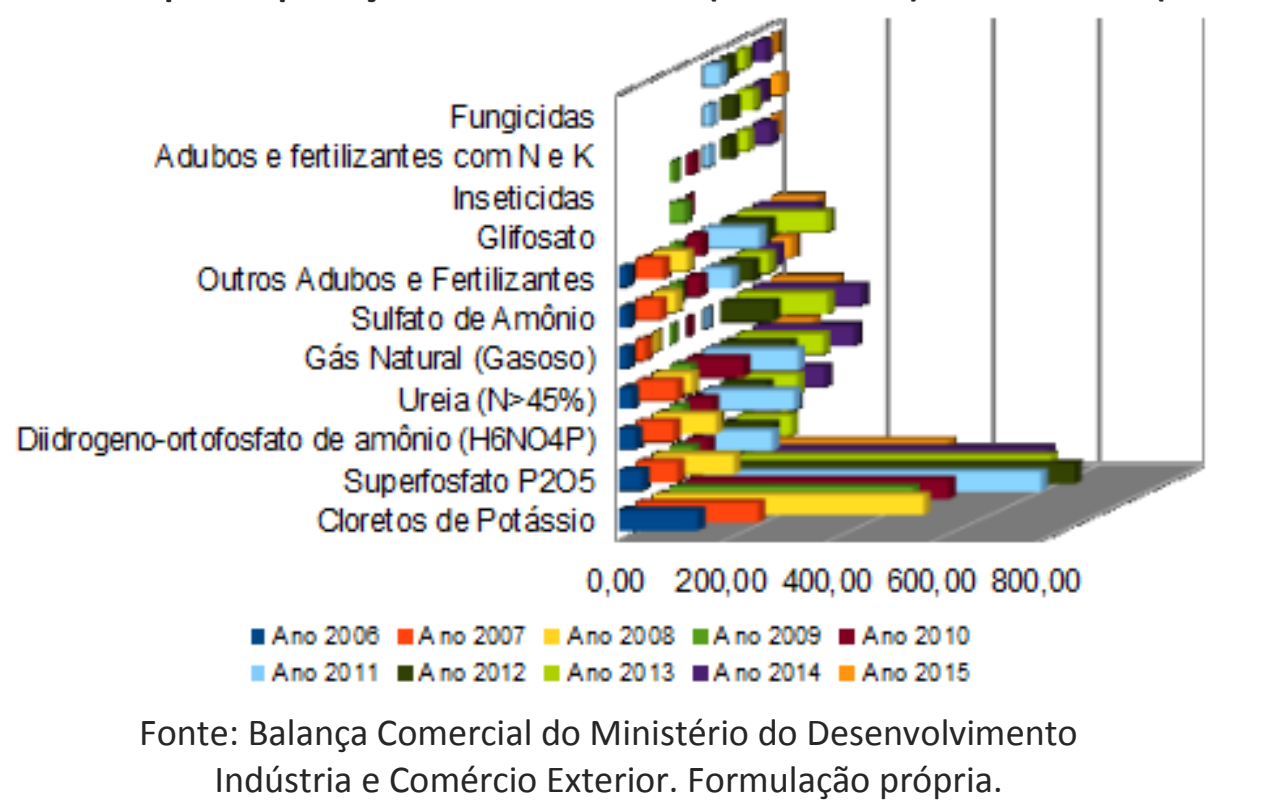

\section{A INSTITUIÇÃO DA POLÍTICA ESTADUAL DE MUDANÇAS CLIMÁTICAS E OS PROBLEMAS SOCIOAMBIENTAIS MATO-GROSSENSES}

São várias e variadas organizações da sociedade civil que representam ribeirinhos, atingidos por megaprojetos, quilombolas, agricultores familiares, dentre outros. Porém, como já mencionado, as organizações de grandes produtores de grãos possuem, historicamente, maior poder econômico e, por isso, maior permeabilidade política nos processos decisórios. Algumas delas, inclusive, possuem sede fixa e infraestrutura de recursos humanos e pesquisa no centro político e administrativo da capital do estado, Cuiabá.

Por esta razão, muitos dos incentivos às medidas de adaptação aos danos e potenciais perdas (econômicas e financeiras) e impactos devidos às mudanças climáticas e ambientais estão centrados, sobretudo, no setor agropecuário em escala industrial. Já o apoio à agricultura familiar beira a estagnação por falta de assistência técnica rural minimamente necessária à produção de alimentos de subsistência.

Se a infraestrutura disponível a produtores em grande escala é bastante avançada, o mesmo não se pode dizer sobre a instalação da Empresa Assistência Técnica e Extensão Rural (EMATER) espalhadas pelo estado: com quadro reduzidíssimo de funcionários e basicamente nenhuma infraestrutura para desenvolvimento de pesquisas ou perspectiva de comercialização de seus produtos, a pequena agricultura permanece abandonada pela estrutura do estado.

Existe uma expectativa para que o Zoneamento Ecológico e Econômico (ZEE) do estado do Mato Grosso seja, uma vez implementado, um dos principais instrumentos para a definição do uso do solo, respaldando políticas ambientais específicas para a conservação, mitigação e adaptação de mudanças ambientais e climáticas. Entretanto, o processo de elaboração e implementação do ZEE mato-grossense é um espelho que reflete as contradições sociais, 
ambientais e sobre o ordenamento territorial exposto.

Resultado de um processo pouco transparente em divulgação de informações, o novo zoneamento ampliaria as áreas passíveis de exploração florestal e agrícola. Houve, por isso, veemente contestação pelas organizações da sociedade civil, apontando incoerências técnicas que permearam muitas etapas do processo de zoneamento.

Os graves problemas de falta de transparência nos processos de participação desde sua formulação até as etapas de estabelecimento evidenciavam-se, por sua vez, em audiências públicas com participação muito restrita das minorias étnicas, muitas vezes sequer consultadas e boicotes a reuniões de representantes da sociedade civil. Por estes motivo o ZEE permaneceu estagnado desde sua elaboração em 2009, interrompido por liminar em 2012 e retomado a partir de 2016 em razão de sua necessidade para a aplicação do Novo Código Florestal no estado.

Todo o processo que envolveu o ZEE do estado foi decisivo para, de um lado, a consolidação do uso do solo de forma a fomentar a produção agrícola voltada para a agroindústria (soja, algodão, milho e cana-de-açúcar) e, de outro, pressionar áreas de conservação, terras indígenas, áreas de produção familiar e ribeirinhos.

É importante entender, neste sentido, que a estrutura institucional brasileira evoluiu de forma a criar segregações de representatividade em diferentes instâncias de maneira a englobar a diversidade da participação social. No entanto, a incorporação desta diversidade não significa que cada grupo social tenha igual influência sobre o processo decisório global (MELLO E GUALDA, 2013). O que se nota é exatamente o contrário: os setores institucionais mais fortes tendem a preterir minorias étnicas em sua composição.

Estruturas institucionais menos influentes no processo como um todo incluem uma maior sociodiversidade. Até mesmo no âmbito dos Conselhos, instâncias como o Conselho Nacional de Meio Ambiente (CONAMA) possui estrutura distinta ao Comitê Nacional de Prevenção e Combate à Tortura (CNPCT), sobretudo na representatividade étnica na composição dos conselheiros: no primeiro, predominam caucasianos, sexo masculino, com renda superior a dois salários-mínimos; no segundo, diversas etnias, de diversos gêneros e com renda, em geral, baixa.

Há, inclusive, fortes e desiguais disputas nos processos de participação nestes espaços: editais de inscrição de conselheiros não divulgados com antecedência superior a uma semana; requisitos inalcançáveis a pequenas organizações e indeferimento de candidaturas por regras cada vez menos claras de votação fazem parte do leque de estratégias de seleção dos membros a serem escolhidos para deliberar assuntos ambientais.

Estas e outras instituições, também, apresentam diferenças estruturais e orçamentárias de forma que umas tenham maior poder de influência que outras no contexto governamental como um todo. No que tange as possibilidades políticas às mudanças climáticas que tem base no meio rural, é importante considerar o quanto as atribuições ministeriais influentes em Fóruns de Mudanças Climáticas que podem repercutir nas cisões entre a atividade agropecuária que se desenvolve em uma estrutura agrária historicamente consolidada.

A composição ministerial em fóruns nacionais que se dedicam às mudanças climáticas 
também refletem as forças de poder que exercem influência sobre as decisões na temática. Mello e Gualda (2013) apontam que o Brasil possui dois ministérios que atuam especificamente sobre o meio rural, o Ministério da Agricultura, Pecuária e Abastecimento (MAPA) e o Ministério do Desenvolvimento Agrário (MDA). O primeiro, que compõe o Fórum Brasileiro de Mudança do Clima (FBMC) pelo Decreto 3.515/2000, trabalha predominantemente com assuntos de política agrícola e pecuária dos atores e agentes do agronegócio.

O segundo, ausente da composição do FBMC, se detém às questões fundiárias e à relação com movimentos e entidades que reivindicam a reforma agrária. Se ambos os perfis colaboram para a produção agrícola nacional e podem influir nas políticas de mitigação e adaptação às mudanças do clima, seria interessante a participação de ambas em fóruns ambientais desta relevância. Dentro das atividades do FBMC, via Grupo de Trabalho (GT) "Mudanças Climáticas, Pobreza e Desigualdades" ${ }^{2}$, também participam organizações mais conectadas ao MDA, ainda com desigualdade de protagonismo nas decisões internas do Fórum.

O FBMC é instrumento institucional para a atuação da Política Nacional de Mudanças Climáticas, a qual se fundamenta sobre os eixos das oportunidades de mitigação, impactos, vulnerabilidades e adaptação, pesquisa, educação, capacitação e comunicação. $O$ seu desdobramento em Políticas Estaduais e Municipais de Mudanças Climáticas visa questões de produção, melhor aproveitamento dos recursos naturais, políticas de incentivo à adoção de energias renováveis, medidas de adaptação, propostas.

De forma análoga e em âmbito estadual, a Política Estadual de Mudanças Climáticas tramita como Projeto de Lei Complementar no 23/2015, tendo em vista o Art. 45 da Constituição Estadual. Nesta proposta de Lei o Sistema Estadual de Mudanças Climáticas implementa a política instituída por esta Lei. Devem integrar este sistema a Secretaria de Estado do Meio Ambiente, o Conselho Estadual do Meio Ambiente, o Fórum Mato-grossense de Mudanças Climáticas (FMMC), os Fóruns Municipais de Mudanças Climáticas e a Defesa Civil.

Ao FMMC compete a formulação e proposição de normas para o estabelecimento da Política Estadual de Mudanças Climáticas, ainda não promulgada, mas, em trâmite na Assembleia Legislativa, em articulação com a Política Nacional de Mudanças Climáticas. O FMMC é composto por representantes de órgãos estaduais e organizações de diferentes grupos dentro sociedade civil que vão desde as representações indigenistas até o setor rural. O Fórum está vinculado à Secretaria Estadual do Meio Ambiente e sua composição disposta no Decreto $\mathrm{n}$ - 2.197 de 22 de outubro de 2009.

Foram nomeadas 43 instituições no FMMC pelo Decreto 2197 de 2009, sendo as 12 Secretarias de Estado, Universidade do Estado de Mato Grosso (UNEMAT) e a ProcuradoriaGeral do Estado (PGE), representando o poder público estadual, Organizações não Governamentais (ONG) e Conselhos, como: Ordem dos Advogados do Brasil (OAB), Conselho Regional de Engenharia e Agronomia (CREA) e Conselho Regional de Biologia (CRBio).

Além de Federações Produtiva como: Federação da Agricultura de Mato Grosso (FA-

2 Compõem este GT as seguintes organizações: Central Única dos Trabalhadores (CUT), Articulação do Semiárido (ASA), Fase, Oxfam, Action Aid, Consea, WWF, Fórum de Mudanças Climáticas e Justiça Social, Vitae Civilis, Fundação Heinrich Böell e a Fundação Oswaldo Cruz. 
MATO), Federação das Indústrias do Estado de Mato Grosso (FIEMT) e A Federação dos Trabalhadores na Agricultura do Estado de Mato Grosso (FETAGRI), Povos Indígenas, Assembleia Legislativa, Ministério Público e Instituições Federais, como: Instituto Brasileiro do Meio Ambiente e dos Recursos Naturais Renováveis (IBAMA), Instituto Nacional de Colonização e Reforma Agrária (INCRA), Fundação Nacional do Índio (FUNAI) e Instituto Nacional de Meteorologia (INMET) como convidados.

Na Câmara Temática da Política Estadual de Mudanças está a Câmara Temática de Mitigação composta pelo GT de Redução de Emissões por Desmatamento e Degradação Florestal (REDD+) e o Comitê de Padrões de Salvaguardas para REDD+, pertinentes à Lei № 9878 de 07/01/2013 que criou o Sistema Estadual de Redução de Emissões por Desmatamento e Degradação Florestal, Conservação, Manejo Florestal Sustentável e Aumento dos Estoques de Carbono Florestal (REDD+) no estado de Mato Grosso.

Ainda sobre a estrutura estadual voltada às Mudanças Climáticas, a Coordenadoria de Mudanças Climáticas e a Coordenadoria de Gestão do Sistema de REDD+ de Mato Grosso estão ligadas à Superintendência de Mudanças Climáticas e Biodiversidade, dentro da Secretaria de Estado do Meio Ambiente do Mato Grosso (SEMA-MT).

O REDD+ é discutido na esfera do governo estadual via SEMA-MT e FMMC. As propostas que giram em torno desta Redução dividem opiniões favoráveis e desfavoráveis até mesmo entre as organizações da fração da sociedade civil com menor permeabilidade política. 0 estabelecimento do sistema de informação de salvaguardas para o programa de REDD+ do estado engloba indicadores que, no intuito de mitigar os problemas socioambientais locais, não aborda o cerne do problema da igualitária possibilidade de exploração dos recursos naturais.

Sendo um dos dez procedimentos necessários para a implementação do REDD+, as salvaguardas são exigências reconhecidas internacionalmente para a criação desses sistemas, consistindo em diretrizes que aumentam os ganhos e diminuem as perdas nas ações relacionadas ao REDD+. Tais salvaguardas definidas pelos Padrões Sociais e Ambientais para REDD+ Social and Environmental Standards (SES), desenvolvido pela Aliança para o Clima, Comunidade e Biodiversidade (CCBA) são baseadas, por exemplo, nas premissas de governança e respeito aos povos indígenas.

Em termos de proteção dos direitos indígenas e o papel das etnias no sequestro de carbono pelos ecossistemas (WALKER, 2014) as opiniões das organizações destes grupos se dividem. Há fortes resistências aos projetos por algumas organizações e, por outro lado, aderências, ainda que com ressalvas às ações do REDD+. Os que discordam alegam a inoperância do REDD+ dentro da realidade agroexportadora do estado e a vulnerabilidade das etnias indígenas e seus territórios aos mecanismos de créditos de carbono.

O FMMC prevê também a criação, pelos municípios, de fóruns locais e o incentivo aos projetos que utilizem o Mecanismo de Desenvolvimento Limpo (MDL). É neste quesito que as municipalidades e a sociedade política local, composta majoritariamente e em seus cargos mais altos por grandes produtores de grãos, entendem as mudanças climáticas como uma oportunidade de mercado. A polarização deste interesse, a partir de uma classe específica 
(dominante), escapa de um planejamento econômico que pense nas potencialidades e limitações dos recursos de forma a um desenvolvimento econômico igualitariamente distribuído.

Se por um lado os grandes produtores aproveitam as oportunidades criadas pelas mecanismos de mitigação e adaptação de mudanças climáticas, pequenos produtores, pantaneiros e etnias indígenas, no entanto, interpretam algumas das estratégias voltadas para o controle das emissões como um fator de preocupação. Os problemas ambientais e a percepção das mudanças climáticas são sentidas e priorizados de maneiras diferentes entre as classes sociais. No Mato Grosso, estas camadas sociais estão representadas, de um lado, por grandes produtores agrícolas; de outro, por agricultores familiares, etnias indígenas e pantaneiros.

É nos espaços de conselhos, fóruns e audiências públicas voltadas ao ambiente ou ao clima, por exemplo, que acaba por se tornar uma reafirmação ideológica, garantindo a hegemonia sobre as classes subalternas (ACSELRAD, 2004, p. 7-11). A categoria "subalterno" descreve as condições de vida de grupos e camadas de classe em situações de exploração ou destituídos dos meios suficientes para uma vida digna (SIMIONATTO, 2009, p.42). Para Gramsci (2002), entretanto, o conceito está entrelaçado à história da sociedade civil e recupera os processos de dominação presentes na sociedade e pela supressão ou marginalização da história dos subalternos.

Aos fóruns que exercem esta hegemonia, determinados por força do Estado, seja ele representado pelos governos federal ou estadual (Bobbio, 1998), surgem outros, alternativos, cuja proposta é contestatória às políticas ambientais e para as mudanças climáticas percebidas como top down, com pouca aplicabilidade nas localidades (ALIER, 2010).

Assim surge o Fórum Mudanças Climáticas e Justiça Social (FMCJS), de atuação também no Mato Grosso e vinculada ao GT do FBMC, como exposto anteriormente. Sua conformação inclui a Articulação do Semiárido Brasileiro (ASA), Conselho Indigenista Missionário (CIMI), Rede Jubileu Sul, Movimento das Mulheres Campesinas (MMC), Movimento dos Pequenos Agricultores (MPA), Conselho Pastoral do Pescadores (CPP), Movimento dos Atingidos por Barragens (MAB), Via Campesina, dentre outros.

Sobre as ações governamentais, esta rede conformada em fórum se posiciona contrária à forma que se estabelecem os empreendimentos energéticos, em geral com baixo investimento e interesse político nas energias renováveis não convencionais, como eólica e solar, especialmente sob a ótica da descentralização e microgeração. Ao invés de diversificar a matriz energética, o governo tem insistido em aumentar a dependência em relação a grandes Usinas Hidrelétricas e usinas termelétricas a gás natural, óleo diesel e carvão.

Segundo o Fórum, apesar da inclusão como GT no FBMC não há suficiente transparência e participação de algumas classes da sociedade nas decisões sobre o planejamento energético. O Conselho Nacional de Política Energética (CNPE), na visão do Fórum, se caracteriza como espaço onde prevalecem os interesses de grandes empresas e grupos políticos.

Tendo em vista estas observações, estes grupos que se conformam em torno do FMCJS se propõem a participar em vista a modelo para o planejamento energético com diversificação e descentralização da matriz de geração de energia elétrica, considerando os direitos humanos das populações atingidas por empreendimentos energéticos. Os entraves a estas 
propostas são as poucas possibilidades de que estas sejam assimiladas pelos governos, os quais consideram que as institucionalidades de participação via fóruns como o FBMC e o FMMC são suficientes como instrumentos de atuação e que, de certa forma, não desestabilizam suas agendas que envolvem a questão energética.

Com o engessamento das agendas em torno à construção das Usinas Hidrelétricas, proliferam-se as denúncias dos impactos socioambientais provocados por estas. Mesmo com as mais diversificadas estratégias de inserção política para o fortalecimento da geração de energia limpa, como a fotovoltaica, ainda não se alcançou um processo decisório que contemple, equitativamente, as demandas de todos os grupos sociais envolvidos.

\section{LIMITAÇÕES DO MODELO POLÍTICO ECONÔMICO E SUAS CONSEQUÊNCIAS ÀS POLÍTICAS ESTADUAIS DE MUDANÇAS CLIMÁTICAS}

É por meio do conhecimento e prática, marcados pelas relações de produção, força de trabalho e infraestrutura que configuram os modos de produção, é que as propriedades do espaço em relação são reveladas (RAFFESTIN, 1993). Estas acabam por configurar como o sistema econômico e político ali se desenvolverão.

O sistema econômico político e a acumulação do capital são ocorrências geográficas, pois somente são possíveis a partir da reorganização espacial, desenvolvimento geográfico desigual e expansão dos limites geográficos (HARVEY, 2005). No caso do meio rural, a expansão das fronteiras agrícolas e concentração de terras são evidentes no estado do Mato Grosso, onde existem 10.687 homologações de terra indevidas registradas (griladas), segundo aponta o levantamento feito entre 2000 e 2006 pela Controladoria Geral da União (CGU).

Assuntos como a diversificação da matriz energética, as políticas de mitigação e adaptação às mudanças climáticas e as políticas rurais têm, assim, uma matriz em comum: funcionam em uma complicada e excludente conformação de relações onde o mercado e Estado são protagonistas, em detrimento das necessidades sociais e ambientais.

As "crises" econômicas e políticas seriam resultados desta conformação. Frente a esta complexidade, as propostas de medidas de mitigação e adaptação às mudanças ambientais globais e às mudanças climáticas encontram um cenário de desigualdades no acesso à terra (organização fundiária), sociais, de recursos naturais e fragilidade política, sendo estes elementos constitutivos da crise econômica estrutural. Desta forma, essas medidas de mitigação e adaptação acabam por funcionar de forma análoga e sincrônica a esta estrutura em crise.

Uma vez que a crise estrutural tem como principal atributo afetar a totalidade do sistema (econômico, social, ambiental, sanitário e financeiro, entre outros), não é coerente ter como estratégia fundamental de solução o tratamento de como se esta crise fosse parcial. Em um sistema operativo e eficiente, crises parciais denotariam medidas de mitigação e adaptação que trouxessem os elementos dissonantes novamente à operacionalidade do sistema geral, o que não acontece.

É dentro da primeira situação que se posiciona como a forma que o tema de Mudanças Climáticas, especificamente, é tratado internacionalmente desde o estabelecimento do Pro- 
tocolo de Kioto e em todas as Conferências das Partes. Apesar de eventos paralelos promovidos por diversas representações da sociedade civil ao redor do mundo, poucas das demandas que acontecem isoladamente às Conferências são levadas em consideração, exatamente porque contestam a estrutura. As Conferências em si são baseadas em possibilidades de mercado dentro do sistema em crise.

Alinhadas com das diretrizes internacionais, a Política de Mudanças Climáticas brasileira, em todas suas esferas governamentais, reproduz a tendência internacional a fim de conseguir vantagens no mercado de carbono. Sua operacionalidade no estado do Mato Grosso deveria estar precedida de muitas etapas do planejamento ambiental e ordenamento territorial consolidadas, junto a políticas socioambientais afirmativas, antes da proposição de medidas como o REDD+. O cenário atual de pouca maturidade democrática e pouca robustez de planejamento ainda é muito incerto e não permite proposições de mitigação e adaptação de impactos ambientais.

Em estruturas políticas municipais dominadas por uma sociedade política também latifundiária que vai desde as Secretarias Municipais de Meio Ambiente até os cargos mais altos das prefeituras, as medidas de mitigação e adaptação são minuciosamente estudadas para estes grupos de maneira que lhes tragam lucros ainda maiores na produção, vantagens e maiores isenções de impostos e certificações que facilitem a exportação desde os países mais flexíveis em termos de sustentabilidade de produção (China), até os mercados mais exigentes (Países Baixos).

Por um lado, e como herança do clientelismo, as municipalidades não só matogrossenses, mas também de maneira geral no Brasil, funcionam por alternância de famílias que historicamente detém o poder e que o mantiveram, apesar da Constituinte. A mesma realidade é compartilhada entre os países latino-americanos.

Estes membros da sociedade civil que emergem à sociedade política se agrupam, neste modelo democrático, por partidos políticos. Estes, ainda que sem ideologia clara, difusos entre as mais diversas coalizões (agrupadas e desagrupadas segundo as forças intervenientes em cada município), levam princípios que lhes parecem afins ou possuem desenvoltura política e permeabilidade que lhes permite a segurança do atendimento de seus interesses. Em geral estes mesmos partidos são menos progressistas e conformam o panorama estadual e nacional expostos nos gráficos apresenta anteriormente.

A conformação das possibilidades políticas territoriais e ambientais no âmbito rural do Mato Grosso é reflexo do histórico de atuação do Estado sobre este meio. O setor agroexportador, ao final da Segunda Guerra, toma força política e econômica, chamando a atenção do Estado para políticas de desenvolvimento nacional e conseguindo dele a infraestrutura necessária para facilitar a comercialização e o escoamento de produtos até os centros urbanos. O Estatuto da Terra consolida o poder de influência política e econômica dos agroexportadores e diminui a possibilidade de reformas estruturais em vista à reforma agrária (MELLO $\mathrm{E}$ GUALDA, 2013

O fomento a agropecuária de exportação foi prostrando, pouco a pouco, os programas que fomentavam a economia doméstica. A soja, como principal produto de exportação, anga- 
riava cada vez mais recursos privados e estatais, área e metas de produtividade. Em resposta a estas estratégias geográficas e geopolíticas desenvolvem-se os movimentos políticos conformados por distintos grupos de atores, sem exclusão da luta de classes, característica como contradição interna da sociedade civil.

Em última instância, a estrutura política agrícola consolidada desconsidera os múltiplos aspectos que Ihe são inerentes (distribuição fundiária, produtividade, culturas cultivadas e grupos de produtores) e, em consequência disto, não equaciona a produção agrícola com a ocupação deste meio. Este panorama complica o estabelecimento de políticas de mudanças climáticas exatamente pela ausência de uma política unificada (MELLO E GUALDA, 2013).

\section{DAS POLÍTICAS ESTADUAIS RURAIS ÀS POLÍTICAS ÀS MUDANÇAS CLIMÁTICAS MATO- GROSSENSES}

Com a crescente concentração de terras, dificuldade de acesso aos recursos do Estado pelos produtores do mercado interno e a impossibilidade de financiamento dentro do processo inflacionário surgem grupos de produtores que, organizados, pressionavam o Estado a ações de apoio à agricultura. Genericamente, pode-se situar três principais perfis que protagonizam as contradições internas da sociedade civil mato-grossense e suas distintas possibilidades de participação política.

Os grandes produtores inseridos no meio político cobravam apoio à agricultura de exportação. Um segundo grupo, de produtores menores e com menor influência política que os primeiros, demandavam o Estado a proteger a agricultura de subsistência e adotar políticas de apoio ao crédito. $O$ terceiro grupo, excluído pela concentração de terras e com enormes desvantagens de inserção política, pressionava o Estado pela reforma agrária por meio dos únicos instrumentos políticos que detinham: a mobilização social e a articulação em redes com outras organizações de semelhante escopo.

A estratificação da sociedade civil por classes sociais e a marginalização das classes com menos poder econômico e político do discurso político econômico dominante podem definir o quão maior ou menor será a divergência ao pensamento hegemônico relativo ao modelo de desenvolvimento baseado no agronegócio (VISVANATHAN, 1997). O quesito decisivo à refutação deste modelo é o questionamento da legitimidade e efetividade da estrutura política e econômica que se desenvolve nos espaços apropriados.

Estas distinções levam às divergências entre as organizações da sociedade civil em relação às suas identidades. Assim, as identidades das redes ambientalistas são dadas pela trajetória histórica reconhecida das organizações da sociedade civil em torno de eixo de atuação e objetivos socioambientais comuns.

As informações das redes são, em geral, tratadas em reuniões, onde os participantes individuais ou das organizações podem intervir na discussão. Este fórum é, então, a técnica de validação de informações e sua comunicação em torno de interesses ou eixos comuns, conduzidos por moderadores. Esta técnica acaba por nomear o escopo das redes já que os assuntos relacionados a seus objetivos são processados em um espaço onde se concentra o 
poder conjunto das organizações.

No estabelecimento das forças de poderes ainda se pode levantar outro aspecto. As relações entre as organizações da sociedade civil trazem para si os mesmos impasses de diferenças de classes inerentes ao conceito de sociedade civil na sua relação com o Estado e o Mercado. Da mesma forma, as redes ambientalistas, em uma escala mais ampla, padecem das mesmas segregações internas e externas.

Independente da escala de relação entre os indivíduos, organizações ou redes e entre estes e o Estado, também haverá em seu âmago e em algumas de suas relações internas (regidas por hegemonias internas) e, principalmente, externas, o conflito. Internamente podem existir várias categorias de Organizações da Sociedade Civil (OSC) ou ONG, dependendo da identificação dos grupos. Movimentos sociais como Movimento dos Trabalhadores Rurais Sem Terra (MST) e MAB e associações universitárias, por exemplo, não se identificam com a nomenclatura ONG.

\section{CONSIDERAÇÕES FINAIS}

Refletindo a complexidade das relações explicitadas nos três parágrafos anteriores, questiona-se a estrutura do FMMC, que elabora os preceitos das políticas estaduais de mudanças climáticas, em duas frentes. A primeira é a constatação das tensões e polaridades derivadas dos distintos posicionamentos e protagonismo dos atores intervenientes neste fórum. A hegemonia política da bancada ruralista é, neste sentido, decisiva para o modelo de política às mudanças climáticas e mudanças ambientais globais adotado para o Mato Grosso. A segunda é da constatação do enfraquecimento das classes sociais marginalizadas política e economicamente nos debates e decisões em tais espaços coletivos estaduais.

Sendo assim, é relativamente simples compreender como se estabelece e a partir de quais atores é formulada a lógica que leva aos planos governamentais de redução de emissões de $\mathrm{CO}_{2}$ no Mato Grosso, terceiro estado no ranking dos que mais contribuíram para a emissão de gases de efeito estufa no Brasil em 2014. As propostas de ação giram em torno da substituição de pastagens de baixo rendimento por cultivos de alta produtividade (soja, milho e algodão), pecuária e florestas plantadas, tendo como foco o aumento da produção.

A redução do desmatamento, ainda que todos os indicadores deste evidenciem seu aumento, apesar das promessas governamentais, e a compensação de áreas passíveis de desmatamento legal e a recuperação de APP e Reserva Legal (RL) permanecem no âmbito das promessas inalcançáveis, juntamente com a proposição de incentivos à agricultura familiar, parcamente representada nos espaços decisórios.

Finalmente, a ideia de uma política voltada às mudanças climáticas ao estado é pouco plausível com tamanha distância do ideal de representatividade esperado para as instituições políticas de uma federação democrática. Mesmo que as organizações e redes ambientalistas demonstrem diferentes estratégias, identidades organizacionais é o grau de aproximação com os tomadores de decisões e a possibilidades de restrições que estas possam representar ao Estado que definirá quem tem maior incidência sobre as agendas governamentais voltadas 
ao ambiente.

\section{REFERÊNCIAS}

Acselrad, H. Conflitos ambientais no Brasil. Rio de Janeiro: Fundação Heinrich Böll, 294 p., 2004.

Alier, J. M. O Ecologismo dos pobres: conflitos ambientais e linguagens de valoração. São Paulo: Contexto. 379 p., 2010.

Bobbio, N.; Matteucci, N., Pasquino, G. Dicionário de Política. Trad. Carmen C. Varriale et ai.; Coord. trad. João Ferreira; Rev. Geral: João Ferreira e Luis Guerreiro Pinto Cacais. Brasília: Editora Universidade de Brasília, la ed., 1998, 1.330p., 1998.

Easton, D. A Systems Analysis of Political Life. New York: John Wiley,177 p., 1965.

Friedrich, C. J. The Philosophy of Law in Historical Perspective. Chicago: University of Chicago Press, 296 p., 1963.

Gramsci, A. Cadernos do cárcere. Tradução de Carlos Nelson Coutinho com a colaboração de Luiz Sergio Henriques e Marco Aurélio Nogueira. Rio de Janeiro: Editora Civilização Brasileira, v. $5 ., 2002$

Harvey, D. A produção capitalista do espaço. Tradução de Carlos Szlak. São Paulo: Annablume, 251 p., 2005.

Mello, L.P; Gualda, V.L. Políticas para o Meio Rural: um Estado e duas abordagens. In: Steinberger, M. Território, Estado e políticas públicas estaduais. Brasília: Ler Editora, 203-226 p., 2013

Raffestin, C. Por uma Geografia do Poder. São Paulo: Ática, 1993.

Shils, E. "Ideology and Civility: On the Politics of the Intellectual". The Sewanee Review. Vol. 66, No. 3, The University of the South 1858-1958: The Centennial Symposia, 450-480 p., 1958. Simionatto, I. "Classes subalternas, lutas de classe e hegemonia: uma abordagem gramsciana". Rev. Katál. Florianópolis v. 12 n. 1 p. 41-49, jan./jun. 2009.

Visvanathan, S. A Carnival for Science: Essays on Science, Technology and Development. Delhi: Oxford University Press, 249 p.,1997.

Walker, W.; Baccini, A.; Schwartzman, S.; et alli. "Forest carbon in Amazonia: the unrecognized contribution of indigenous territories and protected natural areas". Carbon Management. Volume 5, 5-6, 479-485 p., 2014.

Artigo recebido em 08 de fevereiro de 2017.

Aprovado em 24 de abril de 2018. 